Revista do CESP, Belo Horizonte, v. 37, n. 58, p. 11-27, 2017

\title{
Poema sobre palco: cenas de Mário Cesariny
}

\section{Poem on stage: Scenes of Mário Cesariny}

\author{
Maria Silva Prado Lessa \\ Faculdade de Letras, Universidade Federal do Rio de Janeiro, Rio de Janeiro / Brasil \\ mariasplessa@gmail.com
}

Resumo: Na obra poética de Mário Cesariny, há inúmeros poemas identificados como "artes poéticas". A metalinguagem característica dessas composições sugere uma encenação por meio da qual se replica, para o leitor, o processo de feitura do texto que tem em mãos. Fundamse, dessa forma, sucessivas "cenas de escrita" que revelam o gesto dramático da criação poética. Esses poemas assumem, assim, um caráter performático próprio do universo teatral, onde "dizer" equivale a "fazer". Nesse sentido, a poesia de Cesariny se abre ao diálogo com o teatro e demanda uma reflexão acerca da posição do leitor/espectador diante do espetáculo de "reabilitação do real cotidiano" que se põe em cena.

Palavras-chave: literatura portuguesa; Mário Cesariny; surrealismo; cenas de escrita.

Abstract: There are several of Mário Cesariny's poems identified as "arts of poetry". The meta-language of such compositions suggests enacting, replicating to the reader the process of making the text. Successive "scenes of writing" are thus established, revealing the dramatic gesture of poetic creation. Such poems adopt a performative character, which is proper to the theatrical universe, where "saying" equals "doing". Cesariny's poetry is thus open to dialogue with theater and demands a reflection about the position of the reader/spectator towards the spectacle of the enacted "rehabilitation of everyday reality".

Keywords: Portuguese literature; Mário Cesariny; surrealism; scenes of writing. 
Recebido em 30 de outubro de 2017

Aprovado em 5 de janeiro de 2018

\section{Introdução}

Considerado o maior representante do Surrealismo em Portugal, Mário Cesariny iniciou sua trajetória pública nas artes visuais e nas letras quase simultaneamente - expondo pela primeira vez sua obra plástica em 1949, na "I Exposição dos Surrealistas" com telas, desenhos e objetos (CESARINY, 1997, p. 61), e publicando Corpo visível, seu livro de estreia, no ano seguinte. Uma vez que a produção que desenvolveu ao longo de sua vida enveredou por múltiplas linguagens, investigar os traços interartísticos que se manifestam em sua "obra escrita", geralmente tomada como um todo uniforme, torna-se tarefa fundamental.

Este é o caso da abordagem do aspecto dramático da escrita do autor, o qual se faz notar tanto na abundância de poemas que dialogam com o universo teatral - conforme se lê no marcante "You are welcome to Elsinore", o qual remete à tragédia de Shakespeare, Hamlet -, quanto na produção de textos tradicionalmente "dramáticos" - como Um auto para Jerusalém, peça que mereceu duas montagens em Portugal, e Políptika de Maria Klophas, dita mãe dos homens, também encenada no país. A imbricação do plano da poesia com o do drama, contudo, se faz notar especialmente em suas "artes poéticas", poemas nos quais a simultaneidade entre a apresentação de uma teoria poética e a sua prática se assemelha ao gesto espetacular do encenador e do prestidigitador. A metalinguagem característica dessas composições instala uma dimensão processual de sua própria escrita, apontando a existência de um traço teatral na criação poética. Fundam-se, assim, sucessivas "cenas de escrita" que marcam a obra de Mário Cesariny desde seus primeiros livros.

Rosa Maria Martelo, em seu "Cenas da poesia”, aborda a relação entre "artes poéticas" e "cenas de escrita" defendendo que, "quando um poema se transforma em cena de escrita, o que nos é dado a ver é sempre a poética que lhe está subjacente, numa situação que lhe dá corpo, espessura e concreção" (MARTELO, 2010, p. 323). Dessa forma, a leitura das cenas de escrita na poesia de Mário Cesariny revela uma poética que pensa a si mesma como um esforço de reabilitação do espaço público habitado por poeta e leitores. A consciência de ser poesia, consequência 
da autoapresentação dos poemas enquanto processos de escrita, provoca um deslizamento das fronteiras entre arte e vida, como um abalo na quarta parede ficcional que é a garantia, no teatro, da distância entre público e palco. Tal projeto de transformação da vida ganha força quando se observa a frequência com que o cenário urbano é ocupado por um eu-lírico que assume o papel de personagem poeta-ator. Este, "galgando o passeio / o lápis miúdo / no bolso de trás” (CESARINY, 1961, p. 107), indaga a respeito do que escreve:

E isso o que é que é?

$\mathrm{Ah}$, isso, veremos.

Cinema. Teatro.

Poesia, talvez. (CESARINY, 1961, p. 109-110).

\section{Artes poéticas e encenação}

Na obra escrita de Mário Cesariny, muitos são os poemas que representam "artes poéticas" e tematizam os seus processos de composição e de criação. Ao contrário das artes poéticas da Antiguidade e do Renascimento, as quais procuravam definir normas gerais para a escrita, as reflexões acerca da função da poesia e do papel do poeta no mundo nos textos de Cesariny fundam um modo particular de funcionamento. Os teóricos renascentistas, apesar de terem encabeçado um movimento de defesa da poesia e "dos princípios da educação humanista" (GREENE et al., 2012, p. 1158, tradução nossa) com a redação dos diversos tratados de poética, contribuíram para uma limitação das maneiras tanto de se produzir quanto de se falar sobre arte, reduzindoas aos "termos formulados e promulgados pela poética renascentista" (GREENE et al., 2012, p. 1162).

Já no contexto da poesia moderna, o processo de definição de uma poética não tem como objetivo a formação de outros poetas, mas a apresentação de um modo autoral de escrita. João Cabral de Melo Neto, em seu "Poesia e composição - A inspiração e o trabalho de arte", analisa o sentido da teoria da composição na poesia moderna, defendendo que o autor

cria as leis de sua composição. Do mesmo modo que ele cria seu tipo de poema, ele cria seu conceito de poema, e a partir daí, seu conceito de poesia, de literatura, de arte. Cada poeta tem sua poética. Ele não está obrigado a obedecer a nenhuma regra, nem mesmo àquelas que 
em determinado momento ele mesmo criou. [...] O que se espera dele, hoje, é que não se pareça a ninguém, que contribua com uma expressão original. (MELO NETO, 2012, p. 528)

Em sua coincidência entre a prática poética e a defesa de uma teoria de poesia, os poemas que representam artes poéticas parecem demonstrar o seu próprio ato de escrita, desenvolvendo-se processualmente, progressivamente, num ato performativo que se põe diante dos olhos do leitor. A imbricação dos planos da poesia e do drama emerge com especial força ao se perceber o caráter performático que subjaz a essas composições, uma vez que, no universo teatral, a ação em cena é tomada, simultaneamente, como uma representação simbólica de uma ação - ficção - e uma execução objetiva desta - que se dá também no mundo extra-ficcional, onde se encontra o ator que age sobre um palco, ou um poeta que escreve, efetivamente, o poema que diz escrever. Um traço da dramaticidade das artes poéticas reside, portanto, no fato de que, ao representarem um momento de fundação de uma poética autoral, têm como consequência imediata a fundação objetiva desta, na forma de uma cena de escrita. ${ }^{1}$

Nesse movimento, o poeta que se dedica às cenas de escrita dá a ver a encenação, ou a mise en scène, de um poema, expondo os diversos elementos necessários para que empreenda o trabalho com as palavras, pois “a mise en scène é a arte de projetar no espaço aquilo que o dramaturgo só poderia projetar no Tempo", como afirma Adolphe Appia (1954, p. 8 apud PAVIS, 2013, p. 10, tradução nossa). Dessa forma, a encenação da escrita leva o poema a se transformar em um palco, isto é, leva-o a assumir uma dimensão espacial que ultrapassa os limites da página sobre a qual se imprime, tocando os objetos e espaços trazidos à cena e os transfigurando em função da poética que os vincula.

Desde Corpo visível (1950), sua primeira publicação, Cesariny explora uma mise en scène poética que apresente aos leitores o ambiente em que se encontra o "autoractor" (CESARINY, 2004, p. 91) da "letra muito fina extremamente caligráfica” (CESARINY, 1961, p. 205) com a qual escreve o poema, sugerindo, com os elementos postos sobre o

\footnotetext{
${ }^{1}$ É possível perceber, aí, um eco do teatro épico de Brecht, no qual a relação dialética entre teoria e prática é feita por meio de uma direção épica cuja "tarefa maior [...] é exprimir a relação existente entre a ação representada e a ação que se dá no ato mesmo de representar", como afirma Walter Benjamin (1987, p. 88).
} 
palco do poema, as primeiras marcas da poética que será desenvolvida ao longo de sua trajetória artística. A apresentação de cenas do cotidiano urbano será uma marca de Cesariny, na qual se toma a escrita como força de transformação do mundo e o poeta, comparado a um prestidigitador, "organiza um espetáculo" (CESARINY, 2008, p. 45) por meio do qual poderá reestruturar e reabilitar o "país / onde o poeta o poeta é só até à plume" (CESARINY, 2008, p. 83).

Em Discurso sobre a reabilitação do real quotidiano (1952), publicação seguinte a Corpo visível, o autor parece imprimir com especial profundidade o traço teatral da escrita poética que se pensa como maneira de "atravessar fronteiras" (CESARINY, 2008, p. 150). Os poemas do livro reúnem partes de uma realidade fragmentada e representam uma tentativa de "reabilitação" poética da vida "no país no país no país onde os homens / são só até ao joelho" (CESARINY, 2008, p. 83) por meio da apresentação de pequenas cenas urbanas.

Nessas "esquetes", o poeta implora aos habitantes da cidade, com "a mão erecta contra o céu" (CESARINY, 2008, p. 78), que lhe dêem "um pouco de amor" (CESARINY, 2008, p. 78), reconhecendo que entre ele e o real quotidiano permanece uma distância "de certa maneira hiante" (CESARINY, 2008, p. 100):

\author{
a velha que vende bananas \\ o velho roxo de calor \\ o rapaz que grita sacanas \\ dêem-me um pouco de amor (CESARINY, 2008, p. 78)
}

Os traços caracteristicamente surrealistas que se imprimem nos poemas, como o humor negro, a listagem aparentemente despropositada de elementos desencontrados, os jogos de palavras, a narrativa de sonhos e a recorrência de imagens impossíveis, como "um braço de cristal servindo de sirene / às aves trôpegas de tanta música grátis" (CESARINY, 2008, p. 92), sob o riso curto e imediato do estranhamento que provocam, mostram com especial crueza a melancolia de um sujeito que não tem lugar numa cidade que tenta reinscrever sob "um novo real poético (uno)" (CESARINY, 1997, p. 89).

Como um flâneur, o artista solitário traça um percurso característico da poesia moderna desde Baudelaire e de sua manifestação portuguesa em Cesário Verde. Nessa trilha, o que antes se apresentaria como uma deambulação de um sujeito pelas ruas se revela uma grande "Parada", à moda de Rimbaud, a desfilar diante dos olhos de um poeta 
que afirma: "só eu tenho a chave desta parada selvagem" (RIMBAUD, 2007, p. 21). Como nas Iluminações, o percurso traçado pelo eu-lírico se passa no plano da linguagem que ele próprio põe em marcha: trata-se um pronunciamento "a respeito" da reabilitação do real quotidiano que busca imprimir uma nova marca por cima das reabilitações operadas anteriormente, as quais emergem nas repetidas referências a outros poetas que deixaram suas marcas sobre o cenário citadino. Dessa maneira, o trabalho de reestruturação da vida é desenvolvido a partir da montagem de pequenas cenas não apenas de escrita, mas também de leitura de certa tradição moderna da poesia. Recorrer à memória poética será tomado, portanto, como uma maneira por meio da qual se torna possível reabilitar a cidade e reabitar o espaço decadente do cotidiano português. Na tentativa de habitar os diferentes discursos sobre a cidade, o eu-lírico afirma: "a gente às vezes esquece a dor dos outros / o trabalho dos outros o coval / dos outros" (CESARINY, 2008, p. 91).

A solidão do poeta que deambula pelas ruas - ou que, antes, fálas deambular diante de si -, evoca crônicas cesarianas como as de "O sentimento dum ocidental". A expressão moderna de "um desejo absurdo de sofrer" (VERDE, 1977, p. 93) de Cesário Verde, cujos percurso por Lisboa e encontro com os seus habitantes também se dão a partir de um olhar de um sujeito que com aqueles não se identifica, é retomada por Cesariny em seu Discurso de maneira exemplar. Se Cesário evoca "as crônicas navais" (VERDE, 1977, p. 94) e tenta ressuscitá-las em seu poema, numa descrição "sincrética" (MARTELO, 2005, p. 58) de interseção de imagens realistas com a meditação de "um livro que exacerbe" (VERDE, 1977, p. 99), em seu olhar analítico e bipartido de quem vê de "luneta de uma lente só" (VERDE, 1977, p. 98), também o surrealista português recorre à memória literária como maneira de transfiguração de sua experiência cotidiana, não mais partida, mas inteiramente transformada por um sujeito que "us[a] os [s] eus olhos grandes bons e abertos / e [vê] a noite" (CESARINY, 2008, p. 83).

\section{Cena de escrita, cena de leitura}

No poema "XVII" de Discurso sobre a reabilitação do real quotidiano, encontra-se uma característica arte poética cesarinyana estruturada, como outros poemas desse livro, como uma cena de escrita que representa, também, uma cena de leitura de outros poetas - principalmente 
de Cesário Verde, como se verá. Em seu centro, um escritor se põe a trabalhar em seus versos "num café da baixa" (CESARINY, 2008, p. 95), ocupando e transformando, assim, o espaço público:

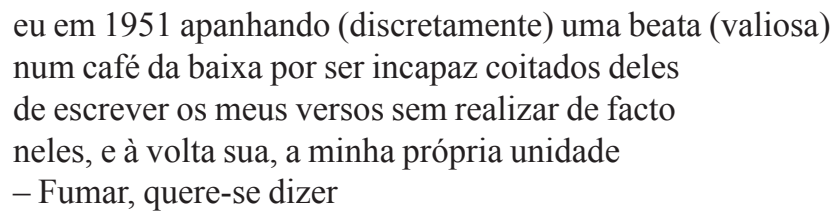

esta, que não é brilhante, é que ninguém esperava ver num livro de versos. Pois é verdade. Denota a minha essencial falta de higiene (não de tabaco) e uma ausência de escrúpulo (não de dinheiro) notável.

[...] (CESARINY, 2008, p. 95)

$\mathrm{Na}$ arte poética que é esse poema, o trabalho artístico ocupa o espaço da cidade, atento aos seus habitantes, em um tempo específico - "eu em 1951" (CESARINY, 2008, p. 95), como escreve - e em diálogo com outros poetas. Estas são características que se repetirão em incontáveis poemas de Cesariny, constituindo os pontos nevrálgicos da poética que desenvolveu. Martelo vê, em "XVII", a "inscrição surrealista da poesia na vida, [...] acto performativo e libertário que mais inclui em si a poesia escrita do que se reduz a ela" (MARTELO, 2010, p. 328). A cena de escrita que se passa na cidade e em seus cafés demonstra, portanto, a necessidade da ocupação dos espaços pelos corpos poéticos de Cesariny e de seus colegas, que frequentavam os cafés lisboetas nas décadas de 1950 e 1960, os quais "podem ser vistos como laboratórios vivos de experiências performativas e experimentais, conhecendo-se mais o impacto que tiveram na história da literatura portuguesa como centros nevrálgicos de vivência, partilha e difusão de experiências estéticas" (DIAS, 2015, p. 168).

A cena de escrita passada "num café da baixa" (CESARINY, 2008, p. 95) trará outro personagem, "o Armando", que compartilha a experiência do eu-lírico, trabalhando, ele também, nos seus versos: 
[...] o Armando, que escreve à minha frente

o seu dele poema, fuma também.

fumamos como perdidos escrevemos perdidamente

e nenhuma posição no mundo (me parece) é mais alta

mais espantosa e violenta incompatível e reconfortável

do que esta de nada dar pelo tabaco dos outros

(excepto coisas como vergonha, naturalmente, e mortalhas) [...] (CESARINY, 2008, p. 95).

Uma vez que a cena é narrada desde um local de encontro com outros poetas e artistas, o poema configurará uma cena de leitura na qual se revela a possibilidade de diálogo com um poeta de outro tempo. Cesário Verde é, assim, convocado como uma "mnemónica literária" (CESARINY, 2000, p. 38), forma de aprendizado e de transformação de um cotidiano degradado. Apesar de tentar apagá-los, a arte poética de Cesariny dialoga com alguns poemas de Cesário, dos quais se destacam "Humilhações" - em que, numa cena que se passa em frente a um teatro, surge uma "fanhosa, infecta, rota, má / [...] uma velhinha suja" (VERDE, 1977, p. 42) a pedir um cigarro ao eu-lírico - e "Contrariedades", no qual se apresenta uma cena de escrita que, além refletir acerca da marginalidade do poeta frente à sociedade, traz também o hábito de fumar como característica do eu-lírico. Cesariny, no entanto, transpõe a cena de escrita do poema de Cesário - passada no interior de um apartamento - para o café, espaço público ocupado pelo poeta e por seu tabaco a infestá-lo.

[...] (que se saiba) é esta a primeira vez

que um poeta escreve tão baixo (ao nível das priscas dos outros) aqui e em parte mais nenhuma é que cintila o tal condicionalismo de que há tanto se fala e se dispõe

discretamente (como quem as apanha). [...] (CESARINY, 2008, p. 95)

A escrita a respeito da vida na cidade e de seus habitantes que se apresenta na obra do poeta de "O sentimento dum ocidental" é lida por Jorge Fernandes da Silveira (1995, p. 9) como "uma forma literal e simbólica de refletir sobre o novo valor da literatura na economia de mercado da época, numa cultura em que o menor dos seus paradoxos não estava no fato de ser colonialista e periférica" - reflexão que ressoa no poema de Mário Cesariny. Ainda segundo o crítico, desde a perspectiva de um poeta que está à margem dessa sociedade, pensar sobre o valor da 
poesia na cidade significa refletir acerca do seu próprio papel de poeta e do seu lugar no mundo. Nesse sentido, apresentando seus eu-líricos como escritores que descrevem cenas de um cotidiano com o qual não compactuam, ambos os poetas inserem em seus poemas o problema da leitura de seus trabalhos, pondo-se à espera da chegada do outro com quem embarcar no "navio de espelhos" (CESARINY, 2008, p. 81). Fartos, os homens dos poemas em questão se apresentam como sujeitos à margem das expectativas burguesas da sociedade portuguesa. Nas composições de Cesário, eles se encontram em situação diametralmente oposta à dos "burgueses" à porta do teatro, das frias mulheres que não lhe dirigem sequer o olhar ou das redações de jornais que recusam "um folhetim de versos" (VERDE, 1977, p. 52) por recearem "que o assinante ingénuo os abandone, / Se forem publicar tais coisas" (VERDE, 1977, p. 53). No texto de Cesariny, o poeta é dotado de uma "essencial falta de higiene" e de "uma ausência de escrúpulo [...] notável" em meio aos frequentadores do café da Baixa, escrevendo "tão baixo" que deverá servir "de lição aos presentes e futuros/ nas taménidas (várias) da poesia local”, as quais "lançam um piar horrível": 2

sirva tudo de lição aos presentes e futuros
nas taménidas (várias) da poesia local.
Antes andar por aí relativamente farto
antes para tabaco que para cesariny
(mário) de vasconcelos (CESARINY, 2008, p. 96)

Nos poemas de ambos os autores, o hábito de fumar se torna matéria de versos e, em "XVII", confunde-se com um léxico pertencente ao universo religioso, católico - que remete também ao vocabulário de Cesário $^{3}$ - a surgir ao lado das imagens de degradação do cenário urbano: as "beatas" são guimbas de cigarro e as "mortalhas", o papel

\footnotetext{
${ }^{2}$ Trata-se da epígrafe do poema na primeira edição de Discurso sobre a reabilitação do real quotidiano, em 1952, na qual se lê uma citação de Carl Wallenstein de $A$ carta e o mundo: "Vivem em harmonia as gaivotas e as taménidas... as gaivotas são brancas e as taménidas lançam um piar horrível..." (CESARINY, 1952 apud SARAIVA, 1986, p. 476). ${ }^{3}$ É o catolicismo o que Rosa Maria Martelo sublinha como sendo o que permanece do passado no presente que Cesário Verde tece em "O sentimento dum ocidental": "A grandeza que a História permite recordar não parece encontrar grandes fios de ligação com o presente [...]. [O] que do passado notoriamente permanece no presente é o Catolicismo, pernicioso e opressivo" (MARTELO, 2005, p. 54).
} 
de enrolar tabaco. A articulação entre a escrita e o cigarro, que emerge na ligação entre a atividade de "escrever os [seus] versos" e o exercício da sua "própria unidade", "fumar", implica uma correspondência entre os seus campos semânticos: a influência poética e o acender as "priscas dos outros", a inspiração e a aspiração da fumaça, além da comparação possível entre a recepção da escrita e a contaminação do ar pelo fumo.

Assumindo um papel duplo de leitor e de escritor, o personagem de Cesariny transporta o poeta cesariano - que "já [fumara] três maços de cigarros / Consecutivamente" (VERDE, 1977, p. 51) - para uma cena em que uma "beata (valiosa)" será apanhada e reacendida. O surrealista se apropria dos textos de Cesário para os dissipar, como fumaça, ao afirmar: "esta, que não é brilhante, é que ninguém esperava ver num livro de versos" e, em seguida, "(que se saiba) é esta a primeira vez / que um poeta escreve tão baixo". Assim, se, na cena de escrita e de leitura que se passa em "XVII", a contaminação do ar pela fumaça representa o desejo de transbordamento da poesia no cotidiano, nela, o poeta ainda está à espera de que possa servir de lição, ou de beata, aos próximos - da mesma maneira que Cesário foi por ele apanhado.

O cigarro assim tratado insere uma questão fundamental no poema de Cesariny que já surgia nos textos de Cesário: o problema de leitura e de incomunicabilidade do poeta - homem alheio à lógica utilitarista $\mathrm{e}$ produtivista burguesa. Em "Humilhações", a questão emerge no momento em que o eu-lírico interpela o seu leitor, chamando-lhe de "burguês", referindo-se a um problema de compreensão:

E, muito embora tu, burguês, me não entendas,

Fiquei batendo os dentes de terror (VERDE, 1977, p. 41, grifos nossos)

O poeta de "Contrariedades", por sua vez, tem seus folhetins recusados por redações de jornais que desejam impor à sua escrita-tomada como "Arte" (VERDE, 1977, p. 53) pelo eu-lírico - um modo de produção vendável. Já o personagem de Cesariny se vê em descompasso com os clientes do café, "coitados deles", por escrever "tão baixo", desejando que a sua atividade "sirva de lição" aos poetas locais presentes e futuros.

Tomando a cena de escrita representada no poema de Cesariny como o momento de fundação de uma poética, percebe-se que o trabalho artístico é concebido como um reaproveitamento do resto (valioso) dos outros e não um trabalho "original e exacto", como o de Cesário. O diálogo entre poetas emerge como uma apropriação da sobra, do inútil 
e do lixo alheio, abarcando uma reflexão acerca do valor da literatura e do espaço que esta ocupa em meio à "secura" da "luz desta cidade" (CESARINY, 2008, p. 88). Personagem principal da cena no café, o poeta é caracterizado como um sujeito a quem falta higiene e escrúpulo, perdido à margem da ordem moral imperante, e que, ao contrário do poeta de Cesário, não se pergunta "o que produz o estudo?", mas deseja inescrupulosamente invadir a realidade cotidiana, transformando-se, ele também, em "tabaco" a ser consumido pelos "presentes e futuros".

Se até aqui a cena de escrita foi tomada como uma narrativa da situação num café onde dois poetas se põem a fumar e a trabalhar em seus versos, a inserção de diversos comentários entre parênteses, acrescida do verso introduzido por um travessão (“-Fumar, quere-se dizer”), assegura a existência de uma outra dimensão teatral no poema de Cesariny que instaura, por sua vez, uma nova cena no poema. Expressões como "(que se saiba)", "(me parece)", "(ao nível das priscas dos outros)", entre muitas outras, apresentam uma "segunda voz" a dialogar com a "voz principal" que se encontra fora dos parênteses.

Destacada pela tipografia, a "segunda voz" expõe a estrutura dramática no texto de Cesariny, evidenciando que a teatralidade em questão não se restringe à cena de um poeta que diz escrever. A mudança de voz, ou a mudança de personagem, sugere que o poema é ele próprio concebido e estruturado como uma cena teatral na qual se estabelece um diálogo entre duas vozes poéticas ${ }^{4}$ : uma, principal, se encontra fora dos parênteses e pertence ao nível do enunciado do poema, outra, coadjuvante, é aquela que se expressa à meia voz, entredita, e que, em sua metalinguagem e autorreferencialidade, remete à enunciação poética. Percebem-se, assim, pelo menos duas cenas no poema: (1) a do poeta que se encontra no café com o Armando, a fumar e a escrever versos ("eu em 1951 apanhando uma beata num café da baixa por ser incapaz coitados deles de escrever os meus versos sem realizar de facto neles, e

\footnotetext{
${ }^{4}$ Éric Benoit, no capítulo "Le relais des voix" de seu Dynamiques de la voix poétique, analisa a introdução de "personagens que falam" nos poemas e o aspecto teatral que conferem à poesia por meio de diversos "efeitos de voz" que ressoam nos poemas. Para o crítico, "la voix, dans la poésie lyrique, dans la poésie comme expression de la personne, est ce par quoi la poésie tend le plus vers le théâtre: la voix est la composante théâtrale de la poésie, avec ses intonations et ses inflexions, et particulièrement quand le poème se présente comme monologue, voire dialogue" (BENOIT, 2016, p. 53).
} 
à volta sua, a minha própria unidade"); (2) aquela que é o próprio poema "XVII", feita como um diálogo entre vozes.

A dimensão metapoética introduzida pelos comentários e explanações do que "quere-se dizer" (CESARINY, 2008, p. 95) faz com que o poema "XVII", portanto, não apenas descreva uma cena de escrita, mas seja o próprio ato de escrita encenado. Sendo a encenação "uma interpretação do texto (ou do script), uma explicação do texto "em ato", (PAVIS, 2011, p. 124), o poema de Cesariny, ao representar sua própria cena de escrita, instaura uma estrutura potencialmente em abismo na qual se articulam indistintamente sua própria teoria de composição e seu ato de criação. Sua arte poética, portanto, não se limita a apresentar uma cena de escrita, trazendo para o poema elementos cenográficos que caracterizam a sua composição, como a ocupação do espaço público pela poesia, a preocupação com a localização da atividade artística num tempo específico, o encontro com outros poetas como forma de transformação de um cotidiano decadente, bem como o ato de apropriação inescrupulosa de outras poéticas. O poeta vai além, transformando sua arte poética na própria cena, estruturando-a sobre um palco.

\section{0 leitor, o espectador}

Devido às particularidades que assumem na escrita moderna, as "artes poéticas" apresentam não apenas um modo único de composição, como um protocolo de leitura a ser seguido, sugerindo uma coincidência entre a demonstração da maneira de funcionamento de uma prática de escrita e o desejo de formação de um novo leitor. Segundo Rosa Maria Martelo, "o que parece estar em causa é sempre a necessidade de fazer derivar de uma nova poética de produção textual a emergência de novos protocolos de leitura, sem os quais seu pleno entendimento nem sua legitimação seriam possíveis" (MARTELO, 2003, p. 90).

O projeto cênico de transformação do cotidiano ganhará fôlego alguns anos após o lançamento de Discurso sobre a reabilitação do real quotidiano, quando Cesariny publica Manual de prestidigitação (1956), livro no qual desenvolve um "manual" de ilusionismo, instrumento que permitiria ao leitor acessar e reproduzir o processo de criação poética, o qual se apresenta como uma digitação, como um "trabalho manual" (CESARINY, 2008, p. 147) cuja aprendizagem se dá por meio de instruções a serem seguidas. Concedendo ao leitor o acesso à "técnica 
mais proibida / da mágica mais procurada" (CESARINY, 2008, p. 137), a seus "truques" - algo que jamais é revelado por um prestidigitador - 0 autor se vê desabrigado de sua posição de proprietário da obra, detentor de sentido e verdade plenos, e dá ao outro a possibilidade de se reapossar do texto para reencená-lo.

Os poemas são transportados para palcos onde novamente se representam cenas de escrita e de leitura de certa tradição da poesia ocidental, onde são dispostos inúmeros elementos cênicos convidados a dialogar uns com os outros, num ensaio aberto que evidencia seu processo criativo. A ilusão, o engano e o fascínio exercidos pela prestidigitação são, assim, trazidos à poesia e à sua potência transformadora. O leitor é conduzido por diversos momentos da criação artística e mágica, desde "Arte de inventar os personagens" (CESARINY, 2008, p. 125), até chegar à cena final do espetáculo, num "Fresco jardim" (CESARINY, 2008, p. 154), passando pelo "Camarim" (CESARINY, 2008, p. 143), por uma "Cena para o final de um terceiro acto" (CESARINY, 2008, p. 129) e pela escolha da cenografia, expressa em "O prestidigitador organiza um espetáculo" (CESARINY, 2008, p. 145), no qual se encontram indicações cênicas próprias do texto dramático, mas apresentadas em forma de poema, descrevendo os elementos que ambientam a cena de escrita:

Há um piano carregado de músicas e um banco

há uma voz baixa, agradável, ao telefone,

há retalhos de um roxo muito vivo, bocados de fitas de todas as cores

[...] (CESARINY, 2008, p. 145).

Se a fundação de uma poética implica uma reflexão acerca não apenas do modo de composição que subjaz aos poemas, mas a respeito dos protocolos de leitura que neles se estabelecem, as cenas de escrita na poesia trazem consigo uma indagação a respeito do quê do espetáculo teatral é transposto tanto para o ato de escrita, quanto para o momento da leitura, numa reflexão que busca um paralelo entre o espectador numa sala de teatro e o leitor que tem um livro nas mãos. Abordando frequentemente o problema da recepção dos poemas, Cesariny parece indicar aos seus leitores a existência de uma transformação de um "assistir ao espetáculo", configuração que garante a distância de autopreservação do espectador, para um "assistir o espetáculo", numa convocação que o retira da poltrona 
e o implica como um coparticipante do processo artístico de "reabilitação do real quotidiano" e como um assistente de prestidigitador.

Apresenta-se, assim, um percurso criativo ao qual os espectadores e leitores são convidados. O percurso na cenografia, ressalta Patrice Pavis, "convida o espectador a descobrir os pontos nevrálgicos da cenografia ou do espaço teatral, a não considerar o cenário como fixo e acabado, mas como um local onde o olhar se investe de maneira diferente conforme os momentos do espetáculo" (PAVIS, 2011, p. 283). Percorrendo o espaço cênico, o espectador (ou o leitor) das cenas de escrita de Cesariny é retirado da sua poltrona e se vê guiado e dirigido por aquele que se assume como o prestidigitador, sendo convocado a integrar o espaço do espetáculo poético que se monta progressivamente:

\section{arte de inventar os personagens}

Pomo-nos bem de pé, com os braços muito abertos e olhos fitos na linha do horizonte

Depois chamamo-los docemente pelos seus nomes e os personagens aparecem (CESARINY, 2008, p. 125)

Estratégia fundamental para abalar a distância segura do leitor, a linguagem injuntiva é frequentemente utilizada por Cesariny. Por meio dela, o autor se dirige ao seu leitor e sugere que este siga algumas ações, por meio de verbos e expressões no imperativo, como "devese", "é preciso", "despe-te", "escuta", "vá", "fiquemos", entre outros. $\mathrm{O}$ uso dos pronomes de segunda pessoa, bem como de primeira pessoa do plural, como no poema acima, apesar de poder ser relacionado a um endereçado que não o leitor, remete também àqueles que se põem a ler. Dessa maneira, a constante interpelação do leitor parece guardar uma chave de leitura fundamental da obra de Cesariny: os poemas tendem a "transgredir o umbral de representação" (GENETTE, 2004, p. 16, tradução nossa), numa ação "metaléptica" - conforme explorada por Genette -, causadora de um deslizamento das fronteiras entre as esferas poética e extrapoética, estética e ética.

A cena de criação artística na qual um espectador é incluído como um participante do processo de construção poética sugere, no limite, o deslocamento do seu leitor da posição de um "espectador incólume" (BLUMENBERG, 1990) - o qual se compraz com sua posição de autopreservação diante da experiência estética -, por meio da criação 
de estratégias para limitar o contato contemplativo e confortável com a obra, transformando-o em personagem necessário para a construção de sentido e que deve agir diante do que lhe ordena a obra:

\author{
Despe-te de verdades \\ das grandes primeiro que das pequenas \\ das tuas antes que de quaisquer outras \\ $[\ldots]$ \\ Então, meu senhor, poderemos passar \\ pela planície nua (CESARINY, 2008, p. 146).
}

O franqueamento das fronteiras ficcionais por meio da interpelação constante do leitor parece simular a transposição, para fora do texto, das possibilidades criadoras e revolucionárias propostas pela "intervenção surrealista", provocando, assim, um profundo abalo na quarta parede ficcional que separa o espectador da ação dramática. Se, no teatro, "[n]a qualidade de voyeur, o público é instado a observar as personagens, que agem sem levar em conta a plateia, como que protegidas por uma quarta parede" (PAVIS, 2011, p. 316), as cenas de escrita dos poemas de Cesariny têm como efeito um abalo na separação imaginária, rompendo a distância contemplativa do espectador frente à representação que se desenvolve sobre o palco-poema, por meio de uma "porosidade" (MARTELO, 2010) que se instala entre a realidade diegética (do texto, ou do palco), e a realidade extradiegética (cotidiana, habitada por leitores e espectadores).

Assim, as cenas de escrita na poesia de Cesariny pressupõem, no limite, cenas de leitura de sua poética, nas quais se busca uma transformação do leitor de poesia em um espectador que assiste o espetáculo, contribuindo como assistente na reabilitação de um cotidiano decadente. Suas cenas de escrita representam, assim, novas maneiras de inscrição da poesia na cidade e não apenas da cidade na poesia. Trata-se de um movimento de transbordamento, para fora das páginas dos poemas, de um olhar sobre o mundo que o transforma, que nele intervém, uma vez que, como defende Martelo (2010, p. 323), os poemas que representam cenas de escrita implicam não apenas a fundação de uma poética, mas uma "ética de escrita". 


\section{Referências}

APPIA, Adolphe. Notes de mise en scène pour L'Anneau de Nibelungen (1891-1892). Revue d'histoire du théâtre. Paris, v. I-II, p. 46-59, 1954.

BENJAMIN, Walter. Magia e técnica, arte e política: ensaios sobre literatura e história da cultura. Obras escolhidas, v. 1. Trad. Sergio Paulo Rouanet. Pref. Jeanne Marie Gagnebin. 3. ed. São Paulo: Editora Brasiliense, 1987.

BENOIT, Éric. Dynamiques de la voix poétique. Paris: Classiques Garnier, 2016.

BLUMENBERG, Hans. Naufrágio com espectador: paradigma de uma metáfora da existência. Lisboa: Assírio Bacelar, 1990.

CESARINY, Mário. Corpo visível. Lisboa: Ed. do Autor, 1950.

CESARINY, Mário. Discurso sobre a reabilitação do real quotidiano. Lisboa: Contraponto, 1952.

CESARINY, Mário. Manual de prestidigitação. Lisboa; Contraponto, 1956.

CESARINY, Mário. Poesia (1944-1955). Lisboa: Delfos, 1961.

CESARINY, Mário. A intervenção surrealista. Lisboa: Assírio \& Alvim, 1997.

CESARINY, Mário. A cidade queimada. Lisboa: Assírio \& Alvim, 2000. CESARINY, Mário. Pena capital. Lisboa: Assírio \& Alvim, 2004.

CESARINY, Mário. Manual de prestidigitação. Lisboa: Assírio \& Alvim (Biblioteca Editores Independentes), 2008.

DIAS, Sandra Isabel Guerreiro. O corpo como texto: poesia, performance e experimentalismo nos anos 80 em Portugal. Coimbra: Faculdade de Letras da Universidade de Coimbra, 2015.

GENETTE, Gérard. Metalepsis: de la figura a la ficción. Trad. Luciano Padilla López. Buenos Aires: Fondo de Cultura Económica, 2004.

GREENE, Roland et alii. The Princeton encyclopedia of poetry and poetics. New Jersey: Princeton University Press, 2012. 
MARTELO, Rosa Maria. Cenas de escrita. In: . Aforma informe. Lisboa: Assírio \& Alvim, 2010. p. 323-343.

MARTELO, Rosa Maria. Modernidade e senso comum: o lirismo nos finais do século XX. Cadernos de Literatura Comparada, Porto, n. 8/9, p. 89-105, 2003.

MARTELO, Rosa Maria. Relendo "O Sentimento dum ocidental". In: VERDE, Cesário. O sentimento dum ocidental. Organização e posfácio de Rosa Maria Martelo. Porto: Campo das Letras, 2005.

MELO NETO, João Cabral de. Poesia e composição - A inspiração e o trabalho de arte. In: TELES, Gilberto Mendonça. Vanguarda europeia e modernismo brasileiro. 20. ed. Rio de Janeiro: José Olympio Editora, 2012.

PAVIS, Patrice. Dicionário de teatro. Trad. Maria Lúcia Pereira, J. Guinsburg, Rachel Araújo de Baptista Fuser, Eudynir Fraga e Nanci Fernandes. São Paulo: Perspectiva, 2011.

PAVIS, Patrice. Contemporary Mise en Scène: Staging theater today. Transl. Joel Anderson. London; New York: Routledge, 2013.

RIMBAUD, Arthur. Iluminações e Uma cerveja no Inferno. Trad., intr. e notas de Mário Cesariny. Lisboa: Assírio \& Alvim, 2007.

SARAIVA, Maria de Fátima Aires Pereira Marinho. O surrealismo em Portugal e a obra de Mário Cesariny de Vasconcelos. Universidade do Porto, 1986. Disponível em: <http://goo.gl/4FV3J6>. Acesso em: jun. 2014.

SILVEIRA, Jorge Fernandes da. Cesário: duas ou três coisas. In: VERDE, Cesário. Cesário Verde: todos os poemas. Organização, introdução e bibliografia de Jorge Fernandes da Silveira. Rio de Janeiro: Sette Letras, 1995. p. 7-23.

VERDE, Cesário. O livro de Cesário Verde: seguido de algumas poesias dispersas. Org. Cabral do Nascimento. Lisboa: Minerva, 1977. 